\title{
An operon encoding three glycolytic enzymes in Lactobacillus delbrueckii subsp. bulgaricus: glyceraldehyde-3-phosphate dehydrogenase, phosphoglycerate kinase and triosephosphate isomerase
}

\author{
Pavel Branny, † Françoise de la Torre and Jean-Renaud Garel \\ Author for correspondence: Jean-Renaud Garel. Tel: +331698234 75. Fax: +33169823129. \\ e-mail: garel@lebs.cnrs-gif.fr
}

Laboratoire d'Enzymologie et de Biochimie Structurales du CNRS, 91198 Gif-sur-Yvette, France

\begin{abstract}
The structural genes gap, pgk and tpi encoding three glycolytic enzymes, glyceraldehyde-3-phosphate dehydrogenase (GAPDH), 3-phosphoglycerate kinase (PGK) and triosephosphate isomerase (TPI), respectively, have been cloned and sequenced from Lactobacillus delbrueckii subsp. bulgaricus ( $L$. bulgaricus). The genes were isolated after screening genomic sublibraries with specific gap and pgk probes obtained by PCR amplification of chromosomal DNA with degenerate primers corresponding to amino acid sequences highly conserved in GAPDHs and PGKs. Nucleotide sequencing revealed that the three genes were organized in the order gap-pgk-tpi. The translation start codons of the three genes were identified by alignment of the $\mathbf{N}$-terminal sequences. These genes predicted polypeptide chains of 338, 403 and 252 amino acids for GAPDH, PGK and TPI, respectively, and they were separated by 96 bp between gap and pgk, and by only 18 bp between pgk and tpi. The codon usage in gap, pgk, tpi and three other glycolytic genes from $L$. bulgaricus differed noticeably from that in other chromosomal genes. The site of transcriptional initiation was located by primer extension, and a probable promoter was identified for the gap-pgk-tpi operon. Northern hybridization of total RNA with specific probes showed two transcripts, an mRNA of $1.4 \mathrm{~kb}$ corresponding to the gap gene, and a less abundant mRNA of $3.4 \mathrm{~kb}$ corresponding to the gap-pgk-tpi cluster. The absence of a visible terminator in the 3 '-end of the shorter transcript and the location of this 3 '-end inside the pgk gene indicated that this shorter transcript was produced by degradation of the longer one, rather than by an early termination of transcription after the gap gene.
\end{abstract}

Keywords: Lactobacillus delbrueckii subsp. bulgaricus, glycolytic enzymes, differential gene expression, transcript stability, codon usage

\section{INTRODUCTION}

Lactobacillus delbrueckii subsp. bulgaricus (called $L$. bulgaricus from here on) is one of the bacteria used by

\footnotetext{
† Present address: Institute of Microbiology, CAS, Videnska 1083, 14220 Prague 4, Czech Republic.

Abbreviations: GAPDH, glyceraldehyde-3-phosphate dehydrogenase (EC 1.2. 1. 12); PGK, 3-phosphoglycerate kinase (EC 2.7.2.3); RLM-RACE, RNAligase-mediated rapid amplification of CDNA ends; TPI, triosephosphate isomerase (EC 5.3.1.1).

The EMBL accession number for the sequence reported in this paper is
} AJ000339. the food industry for large-scale fermentation of milk into cheese and yoghurt, but despite its economic importance, little is known of its biochemistry and genetics. L. bulgaricus produces most (if not all) of the energy required for its growth solely by the glycolytic breakdown of sugars into lactic acid (Kandler \& Weiss, 1986), hence the interest in the structure, organization and expression of the genes involved in the central catabolism of lactose into lactic acid. Several glycolytic genes have been already cloned and characterized in $L$. bulgaricus. The genes encoding lactose permease and $\beta$ galactosidase constitute an operon (Leong-Morgenthaler et al., 1991). A monocistronic operon contains 
only the $l d h D$ gene encoding D-lactate dehydrogenase (EC 1.1.1.28) (Branny et al., 1996). The genes encoding phosphofructokinase (EC 2.7.1.11) and pyruvate kinase (EC 2.7.1.40) are clustered into a bicistronic operon and are transcribed into a single mRNA, even though these enzymes catalyse reactions that are seven steps apart along glycolysis (Branny et al., 1993, 1996).

This study reports the characterization of three other glycolytic genes, the gap gene, encoding glyceraldehyde3-phosphate dehydrogenase (GAPDH; EC 1.2.1.12), the pgk gene, encoding 3-phosphoglycerate kinase (PGK; EC 2.7.2.3) and the tpi gene, encoding triosephosphate isomerase (TPI; EC 5.3.1.1). The three enzymes GAPDH, PGK and TPI catalyse the consecutive reactions that convert dihydroxyacetone phosphate into 3-phosphoglycerate in the central part of the EmbdenMeyerhof-Parnas pathway. These steps involve successively the keto-aldose isomerization between dihydroxyacetone phosphate and glyceraldehyde 3-phosphate catalysed by TPI, the oxidative phosphorylation of glyceraldehyde 3-phosphate into 1,3-bisphosphoglycerate with $\mathrm{NAD}^{+}$as a coenzyme catalysed by GAPDH, and the phosphoryl transfer from 1,3-bisphosphoglycerate to ADP leading to the formation of ATP catalysed by PGK. These enzymes are thus involved in the coupling between carbon oxidation, $\mathrm{NAD}^{+}$reduction and ATP production that is crucial for the generation of energy by anaerobic fermentation. The three genes gap, pgk and tpi have been cloned and sequenced. They are clustered into one operon that begins with gap at the $5^{\prime}$-end and terminates with $t p i$ at the $3^{\prime}$-end. The transcription of this operon has also been studied and suggests that the presence of two transcripts could result in an unequal expression of these three genes. Also, the codon usage in this gap-pgk-tpi operon and in other glycolytic genes appeared to be biased compared with that in other genes from $L$. bulgaricus.

\section{METHODS}

Bacterial strains and growth conditions. L. bulgaricus was grown in MRS medium (Difco) supplemented with $2 \%$ glucose at $42^{\circ} \mathrm{C}$ without aeration. Escherichia coli strains used for cloning and sequencing procedures were grown in Luria broth (LB) supplemented with $100 \mu \mathrm{g}$ ampicillin $\mathrm{ml}^{-1}$ when appropriate, at $37^{\circ} \mathrm{C}$ with vigorous aeration.

DNA manipulations. Chromosomal DNA of $L$. bulgaricus was isolated as described previously (Branny et al., 1993). Plasmid DNA from $E$. coli was isolated by the alkaline-lysis procedure (Birnboim \& Doly, 1979) and further purified on Qiagen columns when necessary. Custom oligonucleotides were purchased from Eurogentec.

Restriction and modifying enzymes were obtained from Boehringer Mannheim or from Promega and used as specified by the manufacturer.

For DNA hybridization, $2 \mu \mathrm{g}$ chromosomal DNA from $L$. bulgaricus was first cleaved with one or two restriction enzymes, and then fractionated according to the size of fragments by electrophoresis on $0.8 \%$ agarose gels. The DNA bands were transferred onto a nylon membrane Hybond- $N$ (Amersham) by vacuum-supported diffusion. The specific probes (see below) were labelled with digoxigenin-dUTP. Blotting, labelling, hybridization, washing and detection were performed using the non-radioactive DNA Labelling and Detection kit from Boehringer Mannheim, following the manufacturer's instructions.

For sequencing, the overlapping fragments containing the genes of interest were cloned into Bluescript II SK $(+) / \mathrm{KS}(+)$ vectors and appropriate subclones were sequenced on both DNA strands using a Pharmacia Automated Laser Fluorescence (ALF) DNA Sequencer. Some of the subclones were sequenced with the Thermosequenase kit from Amersham. All DNA sequences derived from PCR-amplified products were verified by sequencing of three different isolates for correcting any error introduced by Taq polymerase. The sequence data were compiled and analysed using the sequence analysis program DNA-Strider 1.2.

Construction of molecular probes. The oligonucleotides designed according to sequences conserved in various GAPDHs and used as PCR primers to amplify the $3^{\prime}$-end of the gap gene were GAPF(orward), 5' -TIATGACIACIGTICAC-3' (L/MMTTVH), and GAPR(everse), 5'-CATTCGTTGTC(A/G)TACCA-3' (WYDNEW). The two oligonucleotides PGKF, 5'-TGGAA(C/T)GGICCIATGGG-3' (WN-GPMG), and PGKR, 5'-GGCA(A/G)TT(C/G)(C/T) T'TICCTC-3' $[\mathrm{EGK}(\mathrm{E} / \mathrm{Q} / \mathrm{V}) \mathrm{LPG}]$, were designed and used similarly to amplify a part of the $p g k$ gene. The PCR mix $(50 \mu l$ final volume) consisted of template DNA (100 ng), 50 pmol amplimers, dNTP $(200 \mu \mathrm{M}), 1 \times$ Taq DNA polymerase buffer and $1 \mathrm{U}$ Taq DNA polymerase. The reaction was carried out as follows : $94^{\circ} \mathrm{C}$ for $5 \mathrm{~min}$ and then 30 cycles of $37^{\circ} \mathrm{C}$ for $2 \mathrm{~min}$, $72{ }^{\circ} \mathrm{C}$ for $1 \mathrm{~min}$, and $94^{\circ} \mathrm{C}$ for $1 \mathrm{~min}$. The amplified products of predicted size were isolated and cloned into the pMOSBlue $\mathrm{T}$ vector (Amersham). After sequencing, the gap and $p g k$ fragments were subcloned in the proper orientation into pGEM vectors. The antisense RNA probes specific for the gap and pgk genes used for Northern (RNA) and Southern (DNA) hybridizations were generated with SP6 RNA polymerase in the presence of digoxigenin-dUTP [with the RNA Labelling kit (SP6/T7) from Boehringer Mannheim].

RNA analysis. L. bulgaricus total RNA from mid-exponential growth phase was isolated by the classical hot phenol method, with the only modification that the cell lysate treatment with proteinase $\mathrm{K}\left(100 \mu \mathrm{g} \mathrm{ml}^{-1}\right)$ was for $1 \mathrm{~h}$ at $50^{\circ} \mathrm{C}$.

For Northern hybridizations, $10 \mu \mathrm{g}$ total RNA from $L$. bulgaricus was electrophoresed on an agarose denaturing gel, transferred to a nylon membrane and hybridized to each of the antisense RNA probes at $50^{\circ} \mathrm{C}$, in the presence of $50 \%(\mathrm{v} / \mathrm{v})$ formamide. The washing and detection were performed using the Nucleic Acid Detection kit from Boehringer Mannheim. The size of RNAs was determined by comparison to the $0 \cdot 24-9.5 \mathrm{~kb}$ RNA markers set from Gibco-BRL.

For the primer extension experiments, $50 \mu \mathrm{g}$ vacuum-dried total RNA was dissolved in $100 \mu 140 \mathrm{mM}$ PIPES buffer, at $\mathrm{pH}$ 6.4 , containing $1 \mathrm{mM}$ EDTA, $0.4 \mathrm{M} \mathrm{NaCl}$ and $80 \%(\mathrm{v} / \mathrm{v})$ formamide. After the addition of $20 \mathrm{pmol}$ of a ${ }^{32} \mathrm{P}$-end-labelled primer GMP1L (5'-CGGCCAAAACCGTTAATACCAATCTTAAC $-3^{\prime}$ ), a denaturation at $95^{\circ} \mathrm{C}$ for $5 \mathrm{~min}$ and a hybridization at $50^{\circ} \mathrm{C}$ for $8 \mathrm{~h}$, the mixture was precipitated by ethanol, washed with $70 \%(\mathrm{v} / \mathrm{v})$ ethanol and lyophilized. The pellet was dissolved in reverse transcription buffer containing $1 \mathrm{mM} \mathrm{MnCl}, 200 \mu \mathrm{M}$ of each dNTP and $40 \mathrm{U}$ RNasin 
(Promega). cDNA was synthesized with Thermus thermophilus DNA polymerase for $1 \mathrm{~h}$ at $70^{\circ} \mathrm{C}$. In the presence of $\mathrm{Mn}^{2+}$ ions, this enzyme gave much clearer results than avian myeloblastosis virus (AMV) reverse transcriptase. All the RNA present was degraded by a treatment of $30 \mathrm{~min}$ at $37^{\circ} \mathrm{C}$ with RNase A at a final concentration of $50 \mu \mathrm{g} \mathrm{ml}^{-1}$. The cDNA synthesized upon primer extension was precipitated by ethanol, dried under vacuum, dissolved in $3 \mu \mathrm{I}$ TE buffer and $3 \mu \mathrm{l}$ loading dye, and loaded on a $6 \%$ polyacrylamide sequencing gel. The size markers obtained by using the oligonucleotide GMP1L as primer for the sequencing reaction were loaded on the same gel and used to characterize the product of primer extension.

The 3 -end of the processed gap transcript was determined using RNA-ligase-mediated rapid amplification of cDNA ends (RLM-RACE) (Liu \& Gorovsky, 1993). Eighty picomoles of the 16-mer oligonucleotide DFG (5'-TCATCGACTTCGGCAT-3') was phosphorylated with polynucleotide kinase and ligated to $10 \mu \mathrm{g}$ total RNA using T4 RNA ligase. Free oligonucleotides were then eliminated using the RNaid kit from Bio101. cDNA synthesis was primed using the 16-mer oligonucleotide ANTIDFG (5'-ATGCCGAAGTCGATGA$\left.3^{\prime}\right)$, the sequence of which is complementary to that of DFG. The first strand reverse transcription reaction was carried out with AMV reverse transcriptase (Promega) according to the manufacturer's instructions. Excess primer was removed as described above. Half of the cDNA synthesized was used as a template for PCR amplification with one primer, GAP3END (5'-GGTTCGTACTTTGTTGCACTT-3'), designed from a sequence located near the $3^{\prime}$-end of the gap gene, the other primer being the ANTIDFG oligonucleotide. The amplification product was gel-purified, cloned into the pMOSBlue $T$ vector, and sequenced.

Amplification of the $5^{\prime}$-end and promoter region of the $y g a P$ gene by inverted PCR. Chromosomal DNA was digested to completion with SmaI, and the mixture of fragments was allowed to ligate under conditions favouring self-circularization. The product of this ligation was used as a template for PCR amplification with the primers ORFU (5'-TTGCCCCTGGCAGACTGCATT- $\left.3^{\prime}\right)$ and ORFD (5'-GAATTCAGCTCTTCGCCAGCC-3').

\section{RESULTS AND DISCUSSION}

\section{Molecular cloning of DNA fragments containing the gap, pgk and tpi genes}

Alignment of the amino acid sequences known for the GAPDHs and PGKs from different organisms revealed a number of highly conserved regions (Fothergill-Gilmore $\&$ Michels, 1993). For each protein, the sequences of two conserved segments were used to design a pair of degenerate oligonucleotide primers for the production of a specific probe by direct PCR amplification of chromosomal DNA. Each PCR yielded a single amplification product of the size expected from the alignment of amino acid sequences: $430 \mathrm{bp}$ for the gap DNA fragment obtained with the two primers GAPF(orward) and GAPR(everse), and $220 \mathrm{bp}$ for the $p g k$ DNA fragment obtained with the primers PGKF(orward) and PGKR(everse). Each of these two amplification products was cloned and its nucleotide sequence determined. Each DNA fragment contained an ORF giving an amino acid sequence in which all the residues important for the structure and function of the corresponding enzyme, GAPDH or PGK, were conserved. These gap and $p g k$ DNA fragments were subcloned in the proper orientation into pGEM vectors and specific antisense RNA probes were generated with SP6 RNA polymerase. Chromosomal DNA from L. bulgaricus was partially digested with several restriction endonucleases, and each mixture of fragments was analysed by Southern blotting using hybridization with the specific gap and $p g k$ RNA probes to identify the fragments carrying the corresponding genes (data not shown). Three fragments were thus characterized: fragment I was obtained by Pst I cleavage and hybridization with the gap probe only, fragment II by EcoRI cleavage and hybridization with the $g a p$ and $p g k$ probes, and fragment III by EcoRI-Pst I double cleavage and hybridization with the $p g k$ probe only (Fig. 1). These overlapping fragments (Fig. 1) were cloned in the pBluescript II vector. The positive clones were identified by colony hybridization and the recombinant plasmids were isolated. A nested set of unidirectional deletions of these plasmids was subsequently constructed with exonuclease III and mung bean nuclease, essentially as described by Henikoff (1984). Dideoxy sequencing reactions were carried out with 5'end-labelled primers and determined with the ALF DNA sequencer from both strands. DNA sequencing of fragment I showed the presence of a $S m a$ I site that could be used in inverted PCR to obtain fragment IV (Fig. 1). The successive steps of SmaI cleavage of chromosomal DNA, self-circularization of the fragments, linearization by Pst I cleavage, PCR amplification of chromosomal DNA with primers diverging from the PstI site, and cloning and sequencing of the amplified fragment were used to determine the sequence of fragment IV and of the $5^{\prime}$-half of the first ORF (Fig. 1).

\section{Nucleotide sequence of the gap, pgk and tpi genes and their flanking DNA segments}

The essential features and the distances between them of the nucleotide sequences of the $g a p-p g k-t p i$ operon and flanking regions obtained from the four DNA fragments described in Fig. 1 are shown in Fig. 2. The complete sequence contained four ORFs in the same orientation, and the 3 '-end also contained an incomplete ORF oriented in the reverse direction. The ORFs are indicated as boxes in Fig. 2. By a search comparison with the BLAST program, the first ORF was similar to the $y g a P$ gene from Bacillus megaterium, which encodes a hypothetical protein of $37.7 \mathrm{kDa}$ (Schläpfer \& Zuber, 1992). The ATG codon at position 70 was preceded by a weak potential RBS, and was assumed to correspond to the start codon of this ORF. This ORF would end at the stop codon at position 1216, and could encode a protein of 382 residues. This protein would have a size similar to that of the product of the $y g a P$ gene, with about $35 \%$ sequence identity. A region of dyad symmetry followed by several $\mathrm{T}$ residues was present at positions 1189-1216, and could correspond to a rhoindependent terminator. Transcripts corresponding to this region would form a stem-loop secondary structure 


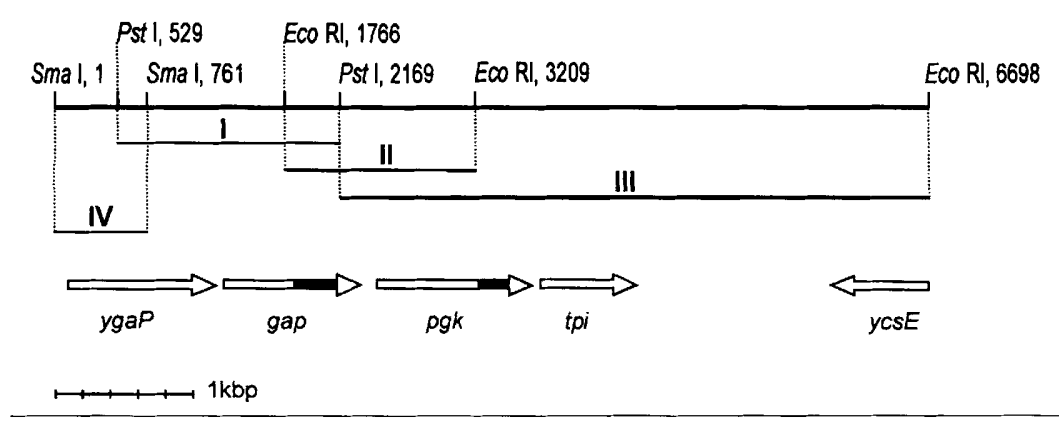

Fig. 1. Physical map of the DNA region around the gap-pgk-tpi operon in $L$. bulgaricus constructed from four different DNA fragments, with the positions of the two specific probes used. The DNA fragments were identified as follows: fragment I was a Pstl fragment recognized by the gap probe; fragment II was an EcoRI fragment recognized by the gap probe only: fragment III was an EcoRI fragment recognized by the pgk probe only; and fragment IV was a Smal fragment obtained by inverted PCR. The regions corresponding to gap and pgk probes are indicated in black. Also shown are the coding regions corresponding to the genes ygaP, gap, pgk, tpi and part of $y c s E$ and the relevant restriction sites.

\section{ygap>}

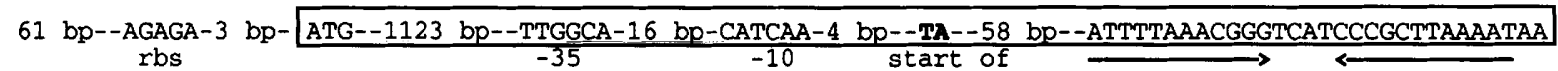
promoter $^{-10} \quad \begin{gathered}\text { start of } \\ \text { transcription }\end{gathered}$

gap>

AATGTTTTTT-10 bp--AGGAGGA-10 bp- ATG----1011 bp----TAA -38 bp--GGCGGAGGGAATTTCTTCCTTCCGCCTTTTTT--
rbs

pok>

tpis -11 bp--AGGAG-9 bp-
rbs

3 ' end of short mRNA

$\angle Y C B E$

--26 bp--- AAAAAACGCTCCTTCGGGAGCGTTTTTTCTTTGTCT-----ca. $1500 \mathrm{bp- \cdots}$ TCA-774 bp--

Fig. 2. Essential features and the distances between them of the nucleotide sequences of the gap-pgk-tpi operon and flanking regions obtained from the four DNA fragments described in Fig. 1. The ORFs are indicated as boxes with only the ATG start and the TAA or TAG stop codons. The transcription starts at $T_{1129}$ and $A_{1130}$ are in bold, and the -35 and -10 sequences of the corresponding potential promoter are given explicitly, together with the putative RBSs preceding the ygaP, gap, pgk and tpi genes. The actual sequences of inverted repeats (indicated by opposing arrows below the sequence) followed by several Ts that could be either rho-independent terminators or mRNA stabilizing stem-loop structures are also shown explicitly. The arrow and interruption in the coding region of pgk indicate the $3^{\prime}$-end determined for the shorter $1.4 \mathrm{~kb}$ mRNA corresponding to the gap gene only.

with a calculated free energy of $-59 \mathrm{~kJ} \mathrm{~mol}^{-1}$ (Tinoco et al., 1973). Primer extension experiments failed to indicate the presence of a promoter, suggesting that transcription of this putative $y g a P$ gene started at a distant site upstream of the ORF and therefore that this gene was the last gene in an operon.

The three other ORFs oriented in the same direction were located between nucleotides 1256 and 2272, between nucleotides 2369 and 3580 , and between nucleotides 3599 and 4357 . These ORFs could be identified unambiguously by comparison of the corresponding amino acid sequences with those in the SWISS-PROT database. The first (in the $5^{\prime}$ to $3^{\prime}$ direction) ORF revealed significant identity to several GAPDHs, the second ORF to several PGKs and the third ORF to several TPIs. The extent of identity was sufficient to conclude that ORF1 corresponded to the gap gene encoding GAPDH, ORF2 corresponded to the $p g k$ gene encoding PGK and ORF3 corresponded to the $t p i$ gene encoding TPI. The level of identity was even high enough to identify the sites of initiation of translation of each gene by aligning their $\mathrm{N}$-terminal amino acid sequences with those of other GAPDHs, PGKs and TPIs. The probable starts of translation of the gap, $p g k$ and $t p i$ genes are the ATG codons located at positions 1256, 2369 and 3599, respectively. In addition, these ATG start codons were preceded by a potential RBS (Fig. 2). The coding sequences were thus separated by 96 bp between $g a p$ and $p g k$, and by 18 bp between $p g k$ 
and $t p i$. The nucleotide sequences of these three ORFs predicted a polypeptide chain of 338 amino acids (with a molecular mass of $36541 \mathrm{Da}$ ) for GAPDH, a chain of 403 amino acids (with a molecular mass of $42685 \mathrm{Da}$ ) for PGK and a chain of 252 amino acids (with a molecular mass of $27365 \mathrm{Da}$ ) for TPI. The amino acid sequences respectively deduced for the products of the $g a p, p g k$ and tpi genes clearly showed homologies with the sequences of GAPDHs, PGKs and TPIs from other bacteria. For GAPDH, the degree of identity ranged between $64 \%$ with the $E$. coli enzyme and $46 \%$ with the Zymomonas mobilis enzyme; for PGK, the identity ranged from $60 \%$ with the Thermotoga maritima enzyme to $43 \%$ with the $Z$. mobilis enzyme; and for TPI, the identity ranged from $66 \%$ with the Lactococcus lactis enzyme to $40 \%$ with the Mycoplasma genitalium enzyme. When conservative amino acid replacements were taken into account, the similarities between the sequences from L. bulgaricus and the others rose to values between 78 and $61 \%$ for GAPDHs, 74 and $61 \%$ for PGKs, and 78 and $58 \%$ for TPIs. These very high degrees of similarity confirmed that the gap, pgk and tpi genes of $L$. bulgaricus indeed encode the enzymes GAPDH, PGK and TPI. Southern hybridizations of restricted chromosomal DNA with the specific gap and $p g k$ probes clearly indicated the presence of a single copy of each gene (data not shown).

Stem-loop structures formed by mRNAs sometimes serve as rho-independent transcription terminators (d'Aubenton Carafa et al., 1990), so the nucleotide sequence was searched for potential stem-loop sites. Downstream of the gap gene, a region of dyad symmetry followed by several $\mathrm{T}$ residues was identified between positions 2311 and 2337 (Fig. 2). This sequence predicts that a rather stable stem-loop structure could be formed by the mRNA with a free energy of $-91 \mathrm{~kJ} \mathrm{~mol}^{-1}$. A second inverted-repeat sequence followed by TTT was found at positions 4384-4411 downstream of the tpi gene. The mRNA transcribed from this region could also form a stem-loop structure, albeit less stable, with a free energy of $-54.5 \mathrm{~kJ} \mathrm{~mol}^{-1}$. The presence of these stem-loop structures resembling rho-independent terminators indicates a possible termination of transcription after the gap and/or the tpi genes (see below).

The DNA segment on the 3 '-side of the tpi gene did not reveal any coding sequence of significant length for $1.4 \mathrm{~kb}$, but an incomplete ORF oriented in the reverse direction was identified further downstream (Fig. 1). The amino acid sequence translated from this ORF showed about $30 \%$ identity to the putative product of the $y c s E$ gene from Bacillus subtilis, which would encode a protein with a chain of molecular mass $29.7 \mathrm{kDa}$ and of unknown function (Yamane $e$ t al., 1996).

\section{Determination of the sizes and ends of transcripts}

The total RNA extracted from $L$. bulgaricus was analysed by Northern hybridization with antisense RNA probes specific for the $3^{\prime}$-end of the gap gene, the $3^{\prime}$-end
A

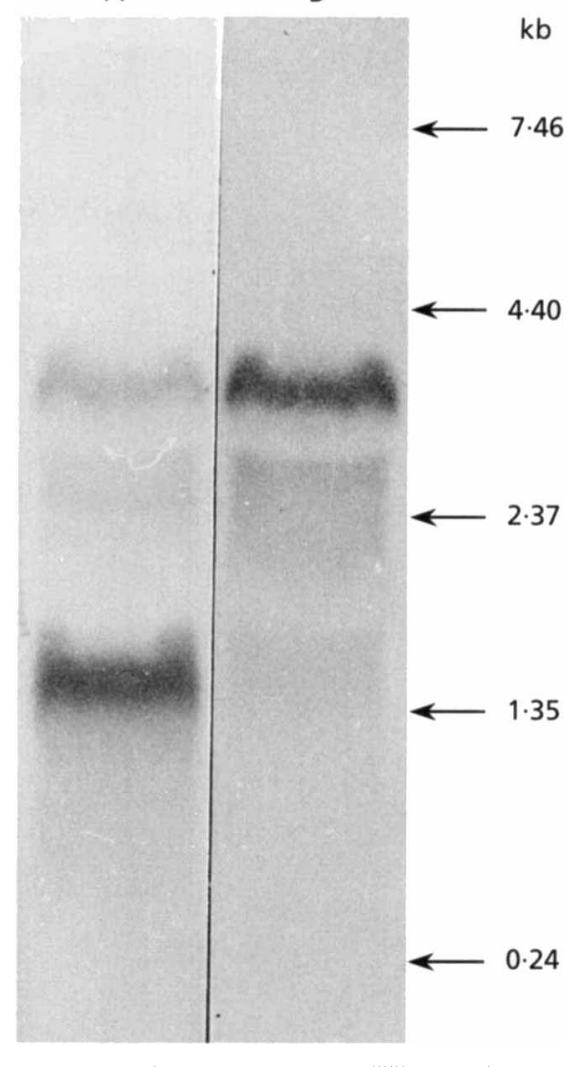

Fig. 3. Determination of the size of the mRNA of the gap, pgk and tpi genes. Total RNA from $L$. bulgaricus was sizefractionated by electrophoresis on a formamide-agarose gel and hybridized with a digoxigenin-labelled gap (lane A) or pgk (lane B) probe. The numbers and arrows on the right correspond to the sizes and migration positions of RNA standards.

of the $p g k$ gene, or the $5^{\prime}$-end of the tpi gene. Hybridization with the gap probe showed two transcripts, a shorter and abundant mRNA of $1.4 \mathrm{~kb}$ and a longer and less abundant one of $3.4 \mathrm{~kb}$, whereas hybridization with either the $p g k$ (Fig. 3) or the tpi (data not shown) probes showed only one transcript of $3.4 \mathrm{~kb}$. The length of $3.4 \mathrm{~kb}$ of the larger RNA was sufficient to correspond to the transcription of the three genes gap, $p g k$ and $t p i$. The shorter abundant RNA of $1.4 \mathrm{~kb}$ could be the result of either a frequent termination of transcription after the gap gene, or an efficient degradation of the full-length transcript of $3.4 \mathrm{~kb}$. The size of $1.4 \mathrm{~kb}$ found for the shorter dominant RNA was slightly larger than that of $1.2 \mathrm{~kb}$ expected from the distance between the transcription start (see below) and the putative termination site at positions 2311-2337 immediately after the gap gene. Therefore, this shorter mRNA could be longer than the gap gene, and contain also the gap-pgk intercistronic region of $96 \mathrm{bp}$ and even a segment of the $5^{\prime}$-part of the $p g k$ gene. The actual mapping of the $3^{\prime}$-end of the shorter mRNA by the RLM-RACE method indeed showed that this transcript 


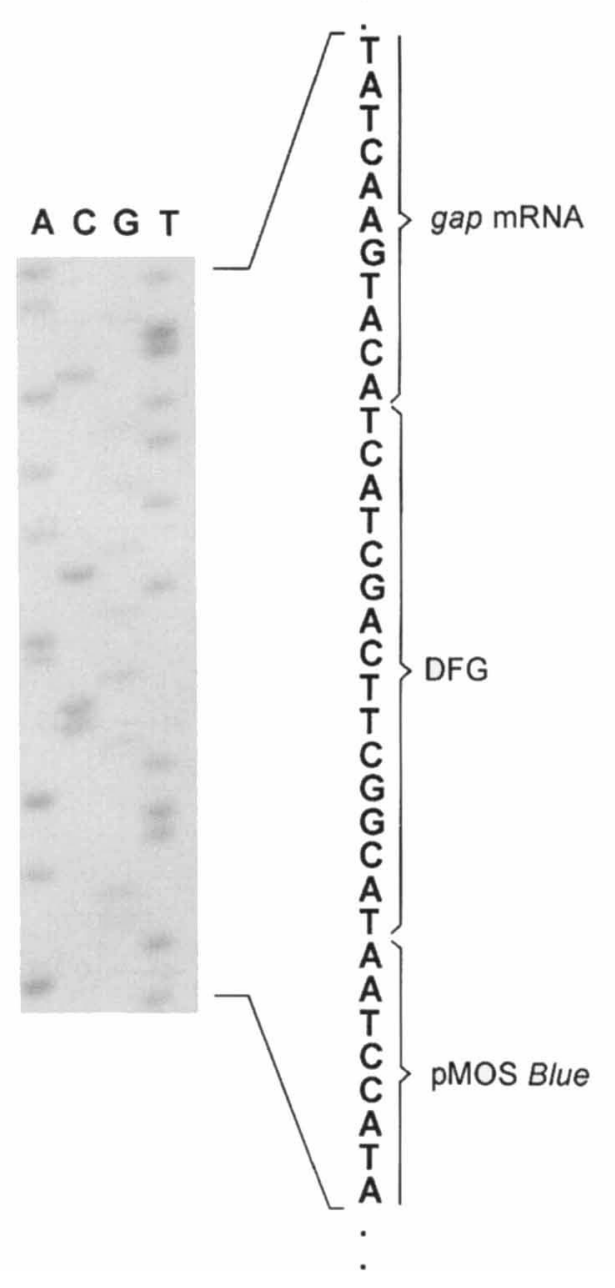

Fig. 4. Mapping of the $3^{\prime}$-end of the $1.4 \mathrm{~kb}$ gap message by the RLM-RACE method. The sequence shown corresponds to the $3^{\prime}-$ end of mRNA, ligated DFG oligonucleotide, and sequencing vector. The sequence of the coding strand is shown on the right.

extended for $139 \mathrm{bp}$ within the $p g k$ gene with its $3^{\prime}$-end located $235 \mathrm{bp}$ downstream of the potential terminator (Fig. 4). Therefore the shorter mRNA encoding the gap gene did not appear to be formed by early termination but by degradation of a longer transcript. This degradation yielded products of different stabilities : a segment of $1.4 \mathrm{~kb}$ at the $5^{\prime}$-end of the long transcript remained stable, while the segment of $2 \mathrm{~kb}$ at the $3^{\prime}$-end was completely degraded. This processing might thus involve an initial specific endonucleolytic cleavage and the marked segmental stabilization of the fragment on the $5^{\prime}$-side of the cleavage site.

The transcription start site was determined by primer extension of the cDNA. Primers complementary to the coding region of the gap gene showed that transcription was initiated at the nucleotide $\mathrm{T}_{1129}$ and/or $\mathrm{A}_{1130}$ (Fig. $5)$. The promoter was identified by its similarity to the consensus sequences found in Gram-positive bacteria

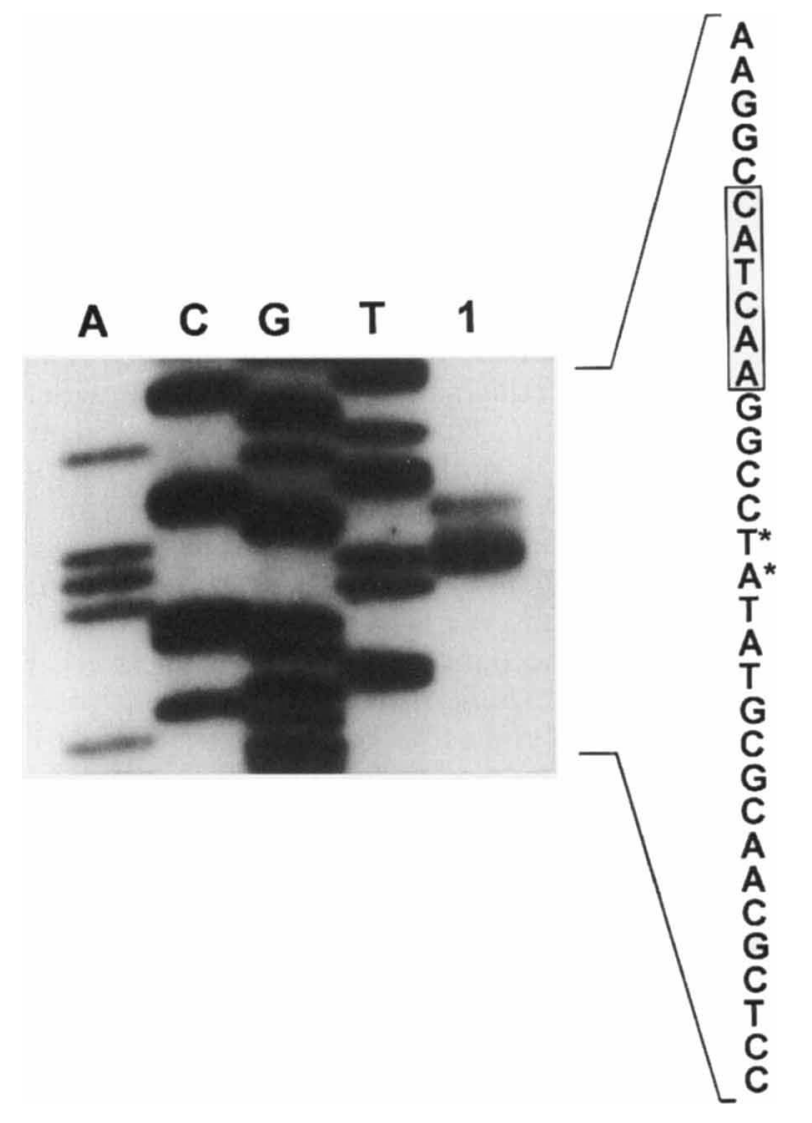

Fig. 5. Determination of the transcription initiation site of the gap-pgk-tpi operon by CDNA primer extension, showing that the major products correspond to initiation at residues $T_{1129}$ and $A_{1130}$. Lane 1 , products of primer extension; lanes $A, C, G$ and $T$, sequence ladder generated with the same primer and the non-coding DNA strand as a template. The relevant DNA sequence is shown on the right. Asterisks indicate the positions of the deduced start sites. The putative -10 hexameric segment of the promoter is boxed.

and E. coli, and its probable sequence was TTGGCA$16 \mathrm{bp}-\mathrm{CATCAA}$. This promoter and the site of transcription initiation were therefore located in the coding region of the putative ygaP gene. Primer extension experiments were also performed to identify a possible promoter upstream of the $p g k$ gene, but no transcription start was found within the gap-pgk intercistronic region using a primer complementary to the $5^{\prime}$-end of the $p g k$ gene.

\section{Comparison of the organization and the transcription of the gap, pgk or tpi genes between different bacteria}

The above results clearly showed that the three glycolytic genes gap, $p g k$ and $t p i$ of $L$. bulgaricus are clustered into an operon. These genes are probably transcribed into a single mRNA starting at a given initiation site, which would be largely degraded later into a smaller stable product. It can be noted that the 
order of the genes along the DNA, gap-pgk-tpi, is different from the order of the corresponding enzymes along glycolysis, TPI-GAPDH-PGK.

In several bacteria, the gap gene is clustered with other genes encoding enzymes of the glycolytic pathway. Corynebacterium glutamicum and B. megaterium possess the same gene cluster of gap, pgk and tpi as that observed in L. bulgaricus (Eikmanns, 1992; Schläpfer \& Zuber, 1992). The gap gene of Z. mobilis is associated with the $p g k$ gene in a bicistronic operon (Eddy et al., 1991). In contrast, the gapA gene encoding the active GAPDH in E. coli is not clustered with any other genes (Branlant \& Branlant, 1985), and the pgk gene is associated with the $f d a$ gene encoding another glycolytic enzyme, fructose-1,6-bisphosphate aldolase (EC 4.1.2.13), and the cryptic gapB gene (Alefounder \& Perham, 1989). Also, in Lactoc. lactis the gap and tpi genes were both found to be monocistronic (Cancilla et al., 1995a, b). Therefore, the genes encoding the same glycolytic enzymes do not have the same organization in different prokaryotes, but there is no obvious explanation for this variability.

There are also differences in the mechanisms by which bacteria control the differential expression of the genes that belong to the same operon as the gap gene. In $C$. glutamicum, the transcription of the gap-pgk-tpi cluster involved mono-, di- and tricistronic mRNAs. The shorter transcript contained the sequence of the gap gene and was produced by termination of the transcription at a site downstream of the gap gene. The longer transcript contained the sequences of all three genes, and an intermediate bicistronic mRNA containing the sequences of the $p g k$ and $t p i$ genes was transcribed from a site of reinitiation located in front of the $p g k$ gene (Schwinde et al., 1993). In Z. mobilis, the expression of the gap-pgk cluster yielded two transcripts: a more abundant mRNA of $1.2 \mathrm{~kb}$ containing only gap, and a minor mRNA of $2.7 \mathrm{~kb}$ containing both genes. Transcript mapping and turnover studies indicated that the shorter mRNA corresponding to the gap gene was a stable degradation product of the full-length transcript. Thus differential expression of the gap and $p g k$ genes was mainly achieved by the increased stability of the $5^{\prime}$-segment of the transcript and the subsequent increased translation of gap (Eddy et al., 1991; Burchhardt et al., 1993). Several arguments suggested that this was also the case in L. bulgaricus, with a shorter transcript corresponding to the gap gene alone $(1.4 \mathrm{~kb})$ deriving from a longer transcript corresponding to the entire gap-pgk-tpi cluster $(3 \cdot 4 \mathrm{~kb})$ by segmental degradation: (i) the gap message showed a defined 3 '-end and extended for $139 \mathrm{bp}$ within the $p g k$ gene (Fig. 4); (ii) the 3 '-segment of the gap message did not reveal any stem-loop terminator-like structure; (iii) the sequence of a potential rho-independent terminator was indeed present immediately after the $3^{\prime}$-end of the gap gene, but it was probably not exploited since no corresponding transcript was observed.

The factors that are responsible for the selective degradation of the $3^{\prime}$-segment of the tricistronic mRNA and the stabilization of its $5^{\prime}$-segment are unknown, but it could be that the stem-loop structure located in the intercistronic region between the gap and $p g k$ genes could serve as a recognition site for an endonucleolytic attack and/or contribute to the stability of the shorter gap transcript. The untranslated 5 -segment of the gap and $g a p-p g k-t p i$ transcripts contained another stemloop structure, that corresponding to the terminator of transcription for the putative ygaP gene. The shorter mRNA with the gap message had thus potential elements of secondary structures in both its $5^{\prime}$ - and $3^{\prime}$-segments, which could explain its stability and its relative abundance (Chen \& Belasco, 1990; Liu et al., 1992).

\section{Codon usage in L. bulgaricus glycolytic genes}

Genes that are strongly expressed in E. coli and Saccharomyces cerevisiae show a highly biased codon usage (Gouy \& Gautier, 1982; Sharp et al., 1986), probably related to the relative abundance of tRNA species (Kurland, 1991). A similar biased codon usage has been reported for the glycolytic genes of E. coli (Médigue et al., 1991) and Lactoc. lactis (Cancilla et al., 1995a). The codon usage in the gap, pgk and tpi genes was close to that in three other glycolytic genes from $L$. bulgaricus, $p f k$, pyk and $l d b D$. However, the codon usage common to these six glycolytic genes showed some differences from that in 10 other chromosomal genes known in L. bulgaricus (Table 1). On one hand, several codons were used less frequently in glycolytic genes, with the following being unused or used only once: CUC (Leu), CUA (Leu), AUA (Ile), UCG (Ser), CCC (Pro), CCG (Pro), ACA (Thr), UAU (Tyr), CAU (His), CAG (Gln), AAU (Asn), GAG (Glu), UGU (Cys), CGA (Arg), AGU (Ser), AGG (Arg), GGA (Gly). On the other hand, some codons were used more frequently in glycolytic genes, such as those for Phe (UUC), Val (GUU), Ser (UCA), Pro (CCA), Thr (ACU), Ala (GCU), Arg (CGU) and Gly (GGU). In general, NNC codons were used more than NNU, and NNA codons more than NNG. This bias in the NNC/U and NNG/A pairs of codons did not correspond to the GC drift postulated for the strongly expressed genes in L. bulgaricus (Pouwels \& Leunissen, 1994). Fermentation provides the energy for the growth of L. bulgaricus, and the glycolytic genes are probably strongly expressed, even though they may not all be expressed to the same high level. This knowledge of the codon usage in L. bulgaricus will be useful for designing probes for the identification of new genes, and for predicting the level of gene expression (Gribskov et al., 1984).

\section{Concluding remarks}

In L. bulgaricus, the genes encoding the enzymes GAPDH, PGK and TPI, which catalyse three adjacent steps in glycolysis, are clustered into a single operon. The expression of this operon probably involves a processing of the long primary transcript and an increased synthesis of GAPDH as compared to PGK and 
Table 1. Codon usage in L. bulgaricus

\begin{tabular}{|c|c|c|c|c|c|}
\hline \multirow[t]{2}{*}{ Amino acid } & \multirow[t]{2}{*}{ Codon } & \multicolumn{2}{|c|}{$\begin{array}{l}\text { Chromosomal } \\
\text { genes }^{*}\end{array}$} & \multicolumn{2}{|c|}{$\begin{array}{c}\text { Glycolytic } \\
\text { genes } \dagger\end{array}$} \\
\hline & & Sum & $\%$ & Sum & $\%$ \\
\hline Phe & TTT & 122 & 44 & 14 & 21 \\
\hline Phe & TTC & 153 & 56 & 54 & 79 \\
\hline Leu & TTA & 65 & 12 & 7 & 4 \\
\hline Leu & TTG & 154 & 27 & 85 & 50 \\
\hline Leu & CTT & 62 & 12 & 30 & 18 \\
\hline Leu & CTC & 73 & 13 & 6 & 4 \\
\hline Leu & CTA & 22 & 4 & - & 0 \\
\hline Leu & CTG & 181 & 32 & 41 & 24 \\
\hline Ile & ATT & 86 & 30 & 36 & 24 \\
\hline Ile & ATC & 194 & 68 & 115 & 75 \\
\hline Ile & ATA & 6 & 2 & 1 & 11 \\
\hline Met & ATG & 126 & 100 & 55 & 100 \\
\hline Val & GTT & 164 & 37 & 135 & 65 \\
\hline $\mathrm{Val}$ & GTC & 176 & 40 & 24 & 12 \\
\hline Val & GTA & 54 & 12 & 41 & 20 \\
\hline $\mathrm{Val}$ & GTG & 50 & 11 & 8 & 4 \\
\hline Ser & $\mathrm{TCT}$ & 49 & 12 & 9 & 9 \\
\hline Ser & $\mathrm{TCC}$ & 83 & 20 & 11 & 11 \\
\hline Ser & TCA & 78 & 19 & 62 & 60 \\
\hline Ser & TCG & 14 & 3 & - & 0 \\
\hline Pro & CCT & 40 & 17 & 13 & 17 \\
\hline Pro & $\mathrm{CCC}$ & 22 & 9 & - & 0 \\
\hline Pro & $\mathrm{CCA}$ & 104 & 45 & 63 & 80 \\
\hline Pro & CCG & 67 & 29 & 2 & 2 \\
\hline Thr & $\mathrm{ACT}$ & 135 & 38 & 106 & 76 \\
\hline Thr & $\mathrm{ACC}$ & 125 & 35 & 24 & 17 \\
\hline Thr & $\mathrm{ACA}$ & 40 & 11 & 3 & 2 \\
\hline Thr & $\mathrm{ACG}$ & 59 & 16 & 7 & 5 \\
\hline $\mathrm{Ala}$ & GCT & 145 & 30 & 125 & 55 \\
\hline Ala & GCC & 200 & 42 & 49 & 22 \\
\hline Ala & GCA & 77 & 16 & 42 & 19 \\
\hline Ala & GCG & 54 & 11 & 10 & 4 \\
\hline Tyr & TAT & 72 & 27 & 6 & 12 \\
\hline Tyr & TAC & 194 & 73 & 45 & 88 \\
\hline$\ddagger$ & TAA & 8 & 80 & 4 & 67 \\
\hline$\ddagger$ & TAG & 2 & 20 & 2 & 33 \\
\hline His & CAT & 31 & 26 & 1 & 2 \\
\hline His & $\mathrm{CAC}$ & 90 & 74 & 47 & 98 \\
\hline Gln & CAA & 113 & 47 & 55 & 93 \\
\hline Gln & $\mathrm{CAG}$ & 126 & 53 & 4 & 7 \\
\hline Asn & AAT & 103 & 36 & 4 & 4 \\
\hline Asn & $\mathrm{AAC}$ & 180 & 64 & 98 & 96 \\
\hline Lys & AAA & 230 & 37 & 8 & 5 \\
\hline Lys & $\mathrm{AAG}$ & 386 & 63 & 146 & 95 \\
\hline Asp & GAT & 150 & 37 & 17 & 10 \\
\hline Asp & GAC & 254 & 63 & 145 & 90 \\
\hline Glu & GAA & 333 & 82 & 150 & 98 \\
\hline Glu & GAG & 75 & 18 & 3 & 2 \\
\hline Cys & TGT & 14 & 30 & 4 & 29 \\
\hline Cys & TGC & 32 & 70 & 11 & 71 \\
\hline$\neq$ & TGA & 0 & 0 & - & 0 \\
\hline Trp & TGG & 74 & 100 & 12 & 100 \\
\hline
\end{tabular}


Table 1 (cont.)

\begin{tabular}{|c|c|c|c|c|c|}
\hline \multirow[t]{2}{*}{ Amino acid } & \multirow[t]{2}{*}{ Codon } & \multicolumn{2}{|c|}{$\begin{array}{c}\text { Chromosomal } \\
\text { genes* }\end{array}$} & \multicolumn{2}{|c|}{$\begin{array}{c}\text { Glycolytic } \\
\text { genes } \dagger\end{array}$} \\
\hline & & Sum & $\%$ & Sum & $\%$ \\
\hline Arg & CGT & 20 & 9 & 35 & 45 \\
\hline Arg & CGC & 56 & 26 & 22 & 29 \\
\hline Arg & CGA & 9 & 4 & - & 0 \\
\hline Arg & CGG & 75 & 35 & 10 & 13 \\
\hline Ser & AGT & 56 & 14 & 3 & 3 \\
\hline Ser & $\mathrm{AGC}$ & 133 & 32 & 17 & 17 \\
\hline Arg & AGA & 41 & 19 & 9 & 12 \\
\hline Arg & AGG & 12 & 6 & 1 & 1 \\
\hline Gly & GGT & 78 & 17 & 91 & 45 \\
\hline Gly & GGC & 235 & 52 & 104 & 51 \\
\hline Gly & GGA & 39 & 9 & 1 & $0 \cdot 5$ \\
\hline Gly & GGG & 99 & 22 & 7 & $3 \cdot 5$ \\
\hline \multicolumn{6}{|l|}{ Total: } \\
\hline Codons & & 6305 & & 2402 & \\
\hline Amino acids & & 6295 & & 2234 & \\
\hline
\end{tabular}

"Based on the nucleotide sequences of the following L. bulgaricus chromosomal genes as given by the GenBank database under the accession numbers given in parentheses: lacY, lactose permease (M55068); lacZ, $\beta$-galactosidase (M55068); ORF306 (D10020); glnA, glutamine synthetase (D10020); $h d h A$, D-hydroxyisocaproate dehydrogenase (X65222); ISL3 (X79114); asnA, asparagine-tRNA ligase (X89438); asnS1, aspartate-ammonia ligase (X89438); pepIP, proline iminopeptidase (L10712); prtB, proteinase (L48487).

†Based on the nucleotide sequences of the glycolytic genes: gap, pgk and $t p i$ (this study); $p f k$, phosphofructokinase (X71403); pyk, pyruvate kinase (X71403); ldhD, D-lactate dehydrogenase (X60220).

$\ddagger$ Stop codon.

TPI. In most bacteria, these enzymes do not show any allosteric regulation (Fothergill-Gilmore \& Michels, 1993), and the activity of each enzyme mainly reflects its amount in the cell. The differential expression of these genes, probably involving mRNA processing and possibly biased codon usage, would allow the equilibration of the activity levels of 'adjacent' enzymes having different kinetic properties, so as to maintain a regular glycolytic flux with no accumulation or depletion of intermediates.

\section{ACKNOWLEDGEMENTS}

This work was supported by grants from the Centre National de la Recherche Scientifique (UPR9063), the Universite Pierreet-Marie Curie (Paris VI) (927-03), and the Danone Group. P.B. is grateful to the Ministère des Affaires Etrangères for travel support.

\section{REFERENCES}

Alefounder, P. R. \& Perham, R. N. (1989). Identification, molecular cloning and sequence analysis of a gene cluster encoding the class II fructose 1,6-bisphosphate aldolase, 3-phosphoglycerate kinase and a putative second glyceraldehyde-3-phosphate dehydrogenase of Escherichia coli. Mol Microbiol 3, 723-732.
d'Aubenton Carafa, Y., Brody, E. \& Thermes, C. (1990). Prediction of rho-independent Escherichia coli transcription terminators. A statistical analysis of their RNA stem-loop structures. $J \mathrm{Mol}$ Biol 216, 835-858.

Birnboim, H. C. \& Doly, J. (1979). A rapid alkaline extraction procedure for screening recombinant plasmid DNA. Nucleic Acids Res 7, 1513-1523.

Branlant, G. \& Branlant, C. (1985). Nucleotide sequence of the Escherichia coli gap gene. Different evolutionary behaviour of the $\mathrm{NAD}^{+}$-binding domain and of the catalytic domain of $\mathrm{D}$ glyceraldehyde-3-phosphate dehydrogenase. Eur J Biochem 150, $61-66$.

Branny, P., de la Torre, F. \& Garel, J.-R. (1993). Cloning, sequencing, and expression of the gene coding for phosphofructokinase in Lactobacillus bulgaricus. J Bacteriol 175, 5344 5349.

Branny, P., de la Torre, F. \& Garel, J.-R. (1996). The genes for phosphofructokinase and pyruvate kinase of Lactobacillus delbrueckii subsp. bulgaricus constitute an operon. J Bacteriol 178, 4727-4730.

Burchhardt, G., Keshav, K. F., Yomano, L. \& Ingram, L. O. (1993). Mutational analysis of segmental stabilization of transcripts from the Zymomonas mobilis gap-pgk operon. J Bacteriol 175, $2327-2333$. 
Cancilla, M. R., Hillier, A. J. \& Davidson, B. E. (1995a). Lactococcus lactis glyceraldehyde-3-phosphate dehydrogenase gene, gap: further evidence for strongly biased codon usage in glycolytic pathway genes. Microbiology 141, 1027-1036.

Cancilla, M. R., Davidson, B. E., Hillier, A. J., Nguyen, N. Y. \& Thompson, J. (1995b). The Lactococcus lactis triosephosphate isomerase gene, $t p i$, is monocistronic. Microbiology 141, 229-238.

Chen, C.-Y. A. \& Belasco, J. G. (1990). Degradation of pufLMX mRNA in Rhodobacter capsulatus is initiated by nonrandom nucleolytic cleavage. J Bacteriol 172, 4578-4586.

Eddy, C. K., Keshav, K. F., An, H., Utt, E. A., Meija, J. P. \& Ingram, L. O. (1991). Segmental message stabilization as a mechanism for differential expression from the Zymomonas mobilis gap operon. $J$ Bacteriol 173, 245-254.

Eikmanns, B. J. (1992). Identification, sequence analysis, and expression of a Corynebacterium glutamicum gene cluster encoding three glycolytic enzymes, glyceraldehyde-3-phosphate dehydrogenase, 3-phosphoglycerate kinase, and triosephosphate isomerase. J Bacteriol 174, 6076-6086.

Fothergill-Gilmore, L. A. \& Michels, P. A. M. (1993). Evolution of glycolysis. Prog Biophys Mol Biol 59, 105-235.

Gouy, M. \& Gautier, C. (1982). Codon usage in bacteria: correlation with gene expressivity. Nucleic Acids Res 10, 70557074 .

Gribskov, M., Devereux, J. \& Burgess, R. R. (1984). The codon preference plot: graphic analysis of protein coding sequences and prediction of gene expression. Nucleic Acids Res 12, 539-549.

Henikoff, S. (1984). Unidirectional digestion with exonuclease III creates targeted breakpoints for DNA sequencing. Gene 28 , 351-359.

Kandler, O. \& Weiss, N. (1986). Regular, nonsporing Grampositive rods. In Bergey's Manual of Systematic Bacteriology, pp. 1208-1234. Edited by P. H. A. Sneath, N. S. Mair, M. E. Sharpe \& J. G. Holt. Baltimore: Williams \& Wilkins.

Kurland, C. G. (1991). Codon bias and gene expression. FEBS Lett 285, 165-169.

Leong-Morgenthaler, P., Zwahlen, M. C. \& Hottinger, H. (1991). Lactose metabolism in Lactobacillus bulgaricus: analysis of the primary structure and expression of the genes involved. J Bacteriol 173, 1951-1957.

Liu, X. \& Gorovsky, M. A. (1993). Mapping the $5^{\prime}$ and 3' ends of Tetrabymena thermophila mRNAs using RNA ligase mediated amplification of cDNA ends (RLM-RACE). Nucleic Acids Res 21, $4954-4960$

Liu, J., Barnell, W. O. \& Conway, T. (1992). The polycistronic mRNA of the Zymomonas mobilis glf-zwf-edd-glk operon is subject to complex transcript processing. J Bacteriol 174, 2824 2833.

Médigue, C., Rouxel, T., Vigier, P., Hénaut, A. \& Danchin, A. (1991). Evidence for horizontal transfer in Escherichia coli speciation. J Mol Biol 222, 851-856.

Pouwels, P. H. \& Leunissen, J. A. M. (1994). Divergence in codon usage of Lactobacillus species. Nucleic Acids Res 22, 929-936.

Schläpfer, B. S. \& Zuber, H. (1992). Cloning and sequencing of the genes encoding glyceraldehyde-3-phosphate dehydrogenase, phosphoglycerate kinase and triosephosphate isomerase from mesophilic Bacillus megaterium: comparison with corresponding sequences from thermophilic Bacillus stearothermophilus. Gene $122,53-62$.

Schwinde, J. W., Thum-Schmitz, N., Eikmanns, B. J. \& Sahm, H. (1993). Transcriptional analysis of the gap-pgk-tpi-ppc gene cluster of Corynebacterium glutamicum. J Bacteriol 175, 39053908 .

Sharp, P. M., Tuohy, T. M. F. \& Mosurski, K. R. (1986). Codon usage in yeast: cluster analysis clearly differentiates highly and lowly expressed genes. Nucleic Acids Res 14, 5125-5143.

Tinoco, I., Jr, Borer, P. N., Dengler, B., Levine, M. D., Uhlenbech, O. C., Crothers, D. M. \& Gralla, J. (1973). Improved estimation of secondary structure in ribonucleic acids. Nat New Biol 246, $40-41$.

Yamane, K., Kumano, M. \& Kurita, K. (1996). The $25^{\circ}-36^{\circ}$ region of the Bacillus subtilis chromosome: determination of the sequence of a $146 \mathrm{~kb}$ segment and identification of 113 genes. Microbiology 142, 3047-3056.

Received 28 July 1997; revised 28 October 1997; accepted 10 November 1997. 